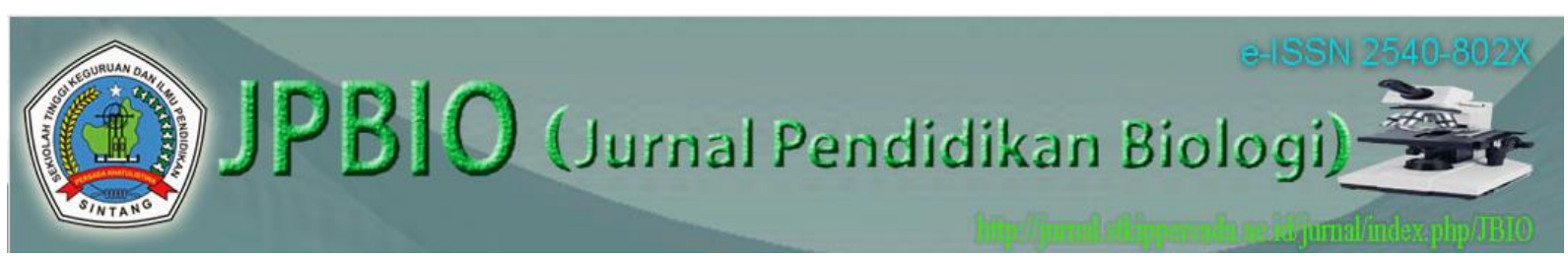

JPBIO (Jurnal Pendidikan Biologi)

Vol. 1 No. 1 November 2016 | 11 - 20

ISSN 2540-802x (Online)

DOI: http://dx.doi.org/10.31932/ JPBIO (Jurnal Pendidikan Biologi)

http://jurnal.stkippersada.ac.id/jurnal/index.php/JBIO

\title{
PENGGUNAAN METODE EKSPERIMEN TERHADAP PSIKOMOTORIK SISWA PADA POKOK BAHASAN PROTISTA
}

\author{
Ririn Rulia Apriliani ${ }^{*}$ \\ ${ }^{1}$ Program Studi Pendidikan Biologi, STKIP Persada Khatulistiwa Sintang \\ E-mail: ririnruliaapriliani@gmail.com*
}

Diterima: 15 April 2016 Direvisi: 12 Mei $2016 \quad$ Disetujui: 07 Oktober 2016

\begin{abstract}
ABSTRAK
Metode eksperimen adalah salah satu metode yang digunakan oleh guru sebagai dasar dalam melaksanakan pembelajaran.Penelitian ini merupakan penelitian eksperimen menggunakan quasy eksperimental design dan nonequivalent control group design dengan menggunakan tes awal dan tes akhir.Penelitian ini menggunakan tekhnik sampling purposive dengan dua variabel, yaitu variabel bebas dan variabel terikat.Data dikumpulkan dengan menggunakan tes dan pengukuran, menggunakan lembar observasi, penialaian dengan rating scale, dan angket. Subjek pada penelitian ini adalah keseluruhan siswa Sekolah Menengah Atas Santun UNTAN Pontianak kelas X, tahun pelajaran 2015/2016. Hasil penelitian ini menunjukkan sebagai berikut: 1) Pembelajaran dengan menggunakan metode eksperimen pada pokok bahasan Protista di kelas eksperimen berdasarkan hasil observasi guru yaitu sangat baik, dan hasil observasi siswa cukup baik. 2) pembelajaran tanpa menggunakan metode eksperimen pada pokok bahasan Protista di kelas eksperimen berdasarkan hasil observasi guru yaitu sangat baik, dan hasil observasi siswa kurang baik. 3) Rata-rata hasil tes awal psikomotorik siswa kelas eksperimen adalah 35,3 dan hasil tes akhir psikomotorik adalah 40,4, dan rata-rata hasil tes awal psikomotorik kelan kontrol adalah 30,90 dan hasil tes akhir adalah 33,04. 4) Terdapat perbedaan secara signifikan psikomotorik hasil tes awal siswa antara kelas eksperimen dan kelas kontrol pada pokok bahasan Protista kelas X Sekolah Menengah Atas Santun UNTAN Pontianak tahun pelajaran 2015/2016, kesimpulan ini berdasarkan hasil analisis data dengan uji-run menggunakan rumus $z$-hitung diperoleh $z_{0}=1,35>1,96$, dan Terdapat perbedaan secara signifikan psikomotorik hasil tes awal siswa antara kelas eksperimen dan kelas kontrol pada pokok bahasan Protista kelas X Sekolah Menengah Atas Santun UNTAN Pontianak tahun pelajaran 2015/2016, kesimpulan ini berdasarkan hasil analisis data dengan uji-run menggunakan rumus $z$-hitung diperoleh $z_{0}=1,35>1,96$. 5) Respon siswa setelah menggunakan metode eksperimen pada pokok bahasan Protista di kelas eksperimen mencapai 75,4815 dengan kategori kuat.
\end{abstract}

Kata kunci: metode eksperimen, penelitian kuantitatif, psikomotorik, protista 


\begin{abstract}
Experimental method is one of the methods that can be used by the teachers as a basis for the implementing of learning. This research is an experimental research using quasy experimental design and nonequivalent control group design with initial test and final test. This research using sampling purposive with two variables, that is independent variable and dependent variable. The data were collected by means and measurement, using observation sheet, assessment with rating scale, and questionnaire. Subjects in this study are all students at Senior High School Santun UNTAN Pontianak (grade first), at academic year 2015/2016. The result of this study are as follows: 1) Learning by experimental method on the subject of Protista in class experimental depending teacher observation result is excellent and the student observation result is adequate, 2) Learning by without experimental method on the subject of Protista in class control depending the teacher observation result is excellet and the student observation result is fault, 3) The average of pre-psycomothoric value is 37,2581 and the post-psycomothoric value is 42,4194 in class experimental, and the average of pre-psycomotohoric value is 33,3871 and the post-psycomothoric value is $37,8788,4) \mathrm{Be}$ found the different as significantly the pret-test of psycomothoric between class experimental dan class control on the subject of Protista Grade $1^{\text {st }}$ Senior High School Santun UNTAN Pontianak on 2015/2016 Academic Year. This hypothesis based on the statistic with run-test using formula $z_{0}$, the result is $Z_{0}=11,35>Z_{\text {tabel }}=1,96$, Be found the different as significantly the post-test of psycomothoric between class experimental dan class control on the subject of Protista Grade $1^{\text {st }}$ Senior High School Santun UNTAN Pontianak on 2015/2016 Academic Year. This hypothesis based on the statistic with run-test using formula $z_{0}$, the result is $\left.Z_{0}=11,35>Z_{\text {tabel }}=1,96,5\right)$ The student responses after using the experimental method on the subject Protista in class experimental is $75,4815 \%$ category sturdy.
\end{abstract}

Keywords: experimental method, quantitative research, psychomotoric, protista

\title{
PENDAHULUAN
}

Secara umum, Guru memiliki peran penting untuk menyalurkan informasi pengetahuandalam sistem pembelajaran di sekolah. Menurut Soetjipto dan Kosasi (2007: 42) "guru sebagai pendidik professional mempunyai citra yang baik di masyarakat apabila dapat menunjukkan kepada masyarakat sekelilingnya". Kegiatan berproses yang sangat fundamental dalam penyelenggaraan jenis dan jenjang pendidikan adalah belajar. Menurut Winataputra (2007: 1.5), "belajar sebagai proses manusiawi memiliki kedudukan dan peran penting, baik dalam kehidupan masyarakat tradisional maupun modern". Pentingnya proses belajar dapat dipahami dari berbagai ungkapan verbal dalam bentuk frasa, peribahasa, kata mutiara, atau puisi yang mengandung makna eksplisit atau implisit tentang pentingnya belajar dalam kehidupan manusia. Sebagai contoh "Belajarlah sampai ke negeri China sekalipun" (Belajarlah tentang apa saja, dari siapa saja dan di mana saja), "Bend the willow when it is young" (Didiklah anak selagi masih muda), "Berakit-rakit ke hulu berenang-renang ke tepian" (Belajar lebih dahulu nanti akan dapat menikmati hasilnya).

Konsep belajar perlu dibangun untuk menumbuhkembangkan potensi belajar individu. Rumusan mengenai sasaran yang ingin dicapai dalam pelaksanaan proses pendidikan dan pengajaran senantiasa mengacu pada tujuan pendidikan nasional yang telah dirumuskan berdasarkan Undang-Undang Nomor 20 Tahun 2003 tentang sistem pendidikan nasional,

Pendidikan nasional bertujuan untuk berkembangnya potensi peserta didik agar menjadi manusia yang beriman dan bertaqwa kepada Tuhan Yang Maha Esa, berakhlak mulia, sehat, berilmu, cakap, kreatif, mandiri, dan menjadi warga Negara yang demokratis serta bertanggung jawab. Konsep ini akan menghasilkan manusia yang sempurna, yakni terbinanya seluruh potensi yang dimiliki baik jasmani, intelektual, emosional, sosial, agama, dan sebagainya. Dengan demikian, ia dapat mengemban tugas hidupnya dengan baik dan 
penuh tanggung jawab, baik yang berkenaan dengan kepentingan pribadi, masyarakat, bangsa, dan Negara.

Oleh karena itu, konsep belajar dalam konteks tujuan pendidikan nasional harus dimaknai sebagai belajar untuk menjadi orang yang: beriman dan takwa kepada Tuhan Yang Maha Esa, ber-akhlak mulia, sehat, berilmu, cakap, kreatif, mandiri, dan menjadi warga Negara yang demokratis dan bertanggung jawab.

Indikator keberhasilan suatu proses pendidikan dan pengajaran tentunya tidak hanya terbatas pada sederetan angka-angka prestasi belajar akan tetapi harus terkait dengan kemampuan siswa merefleksikan program belajarnya dalam bentuk aplikasi sikap positif melalui serangkaian aktivitas yang selektif dan efektif. Kenyataannya, proses pendidikan dan pengajaran yang dikembangkan berbagai lembaga pendidikan tampaknya masih kurang mendapat perhatian yang memadai dari tenaga pengajar. Sehingga proses pengajaran cenderung tidak relevan dengan pola pendekatan atau metode pengajaran yang digunakan. Hal ini menyebabkan sisi kualitas pengajaran yang diharapkan kurang terpenuhi. Oleh karena itu, diperlukan upaya untuk melihat efektivitas suatu pendekatan dan metode pengajaran proses belajar mengajar yang dilakukan dapat berhasil guna dan memudahkan bagi siswa dalam memahami suatu disiplin ilmu atau mata pelajaran yang diterimanya.

Pencapaianindikator keberhasilan tersebutbaiknya guru seharusnya menggunakan banyak strategi dalam proses pembelajaran. Strategi tersebut setidaknya mampu mendorong anak untuk berkreativitas dan mampu mengembangkan potensi anak. Oleh sebab itu, guru dituntut mampu menyesuaikan materi ajar dengan strategi pembelajaran yang digunakan.

Perolehan pengetahuan siswa akan semakin abstrak apabila hanya disampaikan melalui bahasa verbal. Hal ini memungkinkan terjadinya verbalisme, yaitu siswa hanya mengetahui tentang kata tanpa memahami dan mengerti makna yang terkandung dalam kata tersebut dan pada akhirnya dapat menimbulkan kesalahan persepsi dalam diri siswa. Selain dapat menimbulkan verbalisme dan kesalahan persepsi, menyampaikan informasi yang hanya melalui bahasa verbal juga dapat membuat gairah siswa untuk menangkap pesan semakin kurang, karena siswa kurang diajak berpikir dan menghayati pesan yang disampaikan.Padahal untuk memahami sesuatu, perlu adanya keterlibatan siswa, baik fisik maupun psikis.

Proses penilaian keberhasilan siswa pada umumnya dilakukan dalam aspek kognitif. Tentu hal ini tidak salah, tetapi hal ini bisa menjebak guru di mana siswa bisa saja mencontek dengan menyalin hasil jawaban teman atau melihat catatan dan buku.Tentu ini tidak bisa menjadi tolak ukur yang pasti bagi guru.Namun penilaian dalam aspek psikomotorik, guru mengamati secara langsung kegiatan yang dilakukan siswa. Siswa akan merasa diawasi, tanpa bisa melakukan manipulasi. Tentu hasil belajar yang didapat bersifat akurat.

Untuk menilai psikomotorik siswa dapat menggunakan berbagai macam metode pembelajaran, salah satunya dengan menggunakan metode eksperimen. Metode eksperimen adalah suatu cara yang dipergunakan untuk mencapai tujuan pembelajaran yang telah ditetapkan dengan melakukan praktikum atau kegiatan nyata agar siswa memiliki pengalaman belajar yang bersinggungan langsung dengan alam sebagai objek kajian utama mata pelajaran biologi.

Sagala (2003: 220) menyatakan bahwa "Metode eksperimen adalah cara penyajian bahan pelajaran di mana siswa melakukan percobaan dengan mengalami untuk membuktikan sendiri sesuatu pertanyaan atau hipotesis yang dipelajari". Metode eksperimen biasanya digunakan dengan tujuan agar siswa mampu mengaplikasikan semua teori dan konsep yang telah dikuasainya dari semua pelajaran di sekolah ke kegiatan yang nyata.

Berdasarkan uraian latar belakang, dalam kaitan upaya menerapkan metode eksperimen bagi guru biologi dalam pokok bahasan protista di dalam kelas, penulis tertarik untuk melakukan penelitian dengan judul: "Penggunaan Metode Eksperimen Terhadap Psikomotorik Siswa Pada Pokok Bahasan Protista Kelas X Sekolah Menengah Atas Santun UNTAN Pontianak Tahun Pelajaran 2015/2016". 
Tujuan penelitian ini yaitu mengeahui proses pembelajaran siswa menggunakan metode eksperimen di kelas eksperimen Sekolah Menengah Atas Santun UNTAN Pontianak, mengetahui proses pembelajaran siswa tanpa menggunakan metode eksperimen di kelas kontrol Sekolah Menengah Atas Santun UNTAN Pontianak, mengetahui psikomotorik siswa sebelum dan setelah pembelajaran menggunakan metode eksperimen di kelas eksperimen Sekolah Menengah Atas Santun UNTAN Pontianak.mengetahui perbedaan yang signifikan psikomotorik siswa antara kelas eksperimen dan kelas kontrol pada pokok bahasan Protista, mengetahui respon siswa kelas X Sekolah Menengah Atas Santun UNTAN Pontianak terhadap penggunaan metode eksperimen pada pokok bahasan Protista.

\section{METODE PENELITIAN}

Sekolah yang digunakan sebagai tempat penelitian yaitu Sekolah Menengah Atas Santun UNTAN Pontianak dengan jumlah siswa sebanyak 64 orang, dengan XA sebanyak 31 dan XB sebanyak 33 siswa. Pendekatan penelitian yang dilakukan dalam penelitian ini adalah pendekatan penelitian kuantitatif. Pendekatan penelitian kuantitatif didasari oleh filsafat positivisme yang memandang setiap gejala itu dapat diklasifikasikan, relative tetap, konkrit, teramati, terukur, dan hubungan gejala bersifat sebab akibat. Bentuk penelitian yang digunakan dalam penelitian ini adalah eksperimen. Penelitian eksperimen yang digunakan adalah quasy eksperimental design (desain quasi-eksperimen).Pengambilan sampel pada penelitian ini menggunakan teknik samplingpurposive.Teknik penelitian sebagai cara yang dapat ditempuh untuk mengumpulkan data dalam penelitian ini yaitu dengan teknik observasi langsung yaitu alat pengumpulan data berupa lembar observasi yang ditujukan untuk siswa berupa pertanyaan tentang proses pembelajaran dengan metode eksperimen di kelas eksperimen, teknik pengukuran yaitu dengan penilaian unjuk kerja (performan), teknik komunikasi tak langsung yaitu dengan angket.

\section{HASIL DAN PEMBAHASAN PENELITIAN}

Kegiatan yang dilakukan pada tindakan pendahuluan adalah meminta ijin kepada kepala sekolah dan melakukanobservasi terhadap kegiatan belajar mengajar di kelas X serta wawancara terhadap guru kelas XSekolah Menengah Atas Santun UNTAN Pontianak. Berdasarkan hasil observasi awal yang telahdilakukan menunjukkan bahwa guru masih menggunakanmetode demonstrasi.Hal inimengakibatkan siswa psikomotorik siswa kurang aktif dalam mengikuti kegiatanpembelajaran sehingga aktivitas belajar siswa masihtergolong rendah. Selain aktivitas belajar, hasil belajarpunmasih relatif rendah, rata-rata psikomotorik siswa kelas XA yaitu 43,45 dan kelas XB yaitu 39,36.

Hasil penelitian menunjukkan bahwa proses pembelajaran yang dilakukan menggunakan metode eksperimen pada pokok bahasan protisa di kelas sangat baik baik, terbukti dengan hasil observasi guru pertemuan pertama yaitu $100 \%$ dan hasil obervasi siswa pada pertemuan pertama yaitu $41,74 \%$. Proses pembelajaran yang dilakukan tanpa menggunakan metode eksperimen pada pokok bahasan Protista di kelas kontrol sangat baik, terbukti dengan hasil observasi guru pertemuan pertama yaitu $100 \%$ dan hasil observasi siswa yaitu berada dalam kategori kurang baik, terbukti dengan hasil observasi siswa pada pertemuan pertama yaitu $41,74 \%$ dan Data hasil analisis aktivitas belajar siswa pada pertemuan I disajikan pada Tabel 1 berikut:

Tabel 1. Persentase Rata-rata Aktivitas Belajar

\begin{tabular}{llll}
\hline \multirow{2}{*}{ No. } & \multirow{2}{*}{ Kelas } & \multicolumn{2}{c}{ Persentase Rata-Rata } \\
\cline { 3 - 4 } & & \multicolumn{2}{c}{ Pertemuan I } \\
\cline { 3 - 4 } & & Observasi Guru & Observasi Siswa \\
\hline 1 & XA & $100 \%$ & $33,76 \%$ \\
\hline 2 & XB & $100 \%$ & $41,74 \%$ \\
\hline
\end{tabular}




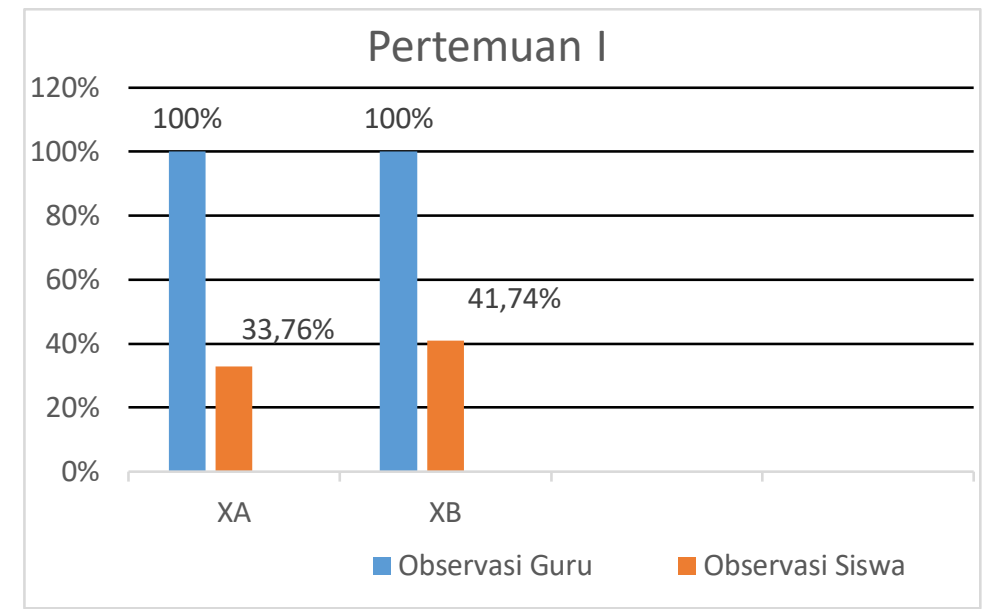

Gambar 1. Diagram Aktivitas Guru dan Siswa Pertemuan 1

Proses pembelajaran yang dilakukan menggunakan metode eksperimen pada pokok bahasan protisa di kelas sangat baik baik, terbukti dengan hasil observasi guru pertemuan kedua yaitu $100 \%$, dan hasil observasi siswa pada pertemuan kedua yaitu $46,90 \%$. Proses pembelajaran yang dilakukan tanpa menggunakan metode eksperimen pada pokok bahasan Protista di kelas kontrol sangat baik, terbukti dengan hasil observasi guru pertemuan kedua yaitu $100 \%$, adapun hasil observasi siswa yaitu berada dalam kategori kurang baik, terbukti dengan hasil observasi siswa pada pada pertemuan kedua yaitu 46,90\%. Data hasil analisis aktivitas belajar siswa pada pertemuan II disajikan pada Tabel 2 berikut:

Tabel 2. Persentase Rata-rata Aktivitas Belajar

\begin{tabular}{|c|c|c|c|}
\hline \multirow{3}{*}{ No. } & \multirow{3}{*}{ Kelas } & \multicolumn{2}{|c|}{ Persentase Rata-Rata } \\
\hline & & \multicolumn{2}{|c|}{ Pertemuan II } \\
\hline & & Observasi & Observasi \\
\hline 1 & XA & $100 \%$ & $\frac{30 \times 0}{39.47 \%}$ \\
\hline 2 & XB & $100 \%$ & $46,90 \%$ \\
\hline
\end{tabular}

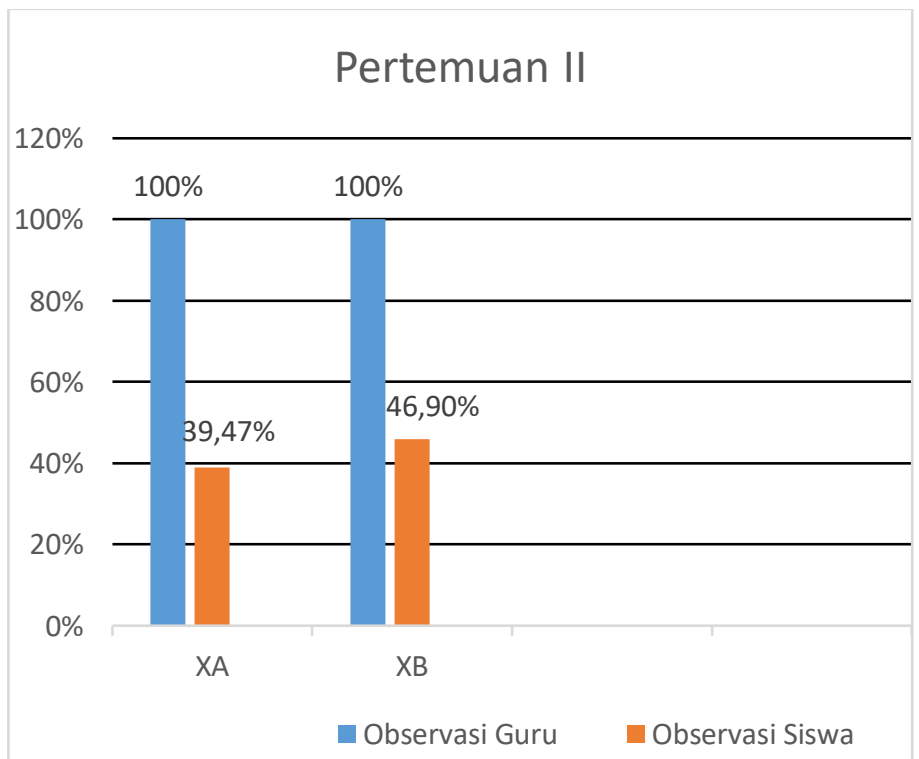

Gambar 2. Diagram Aktivitas Guru dan Siswa Pertemuan 2 
Selain aktivitas guru dan sisa yang mengalamin peningkatan, rata-rata nilai psikomotorik siswa juga mengalami peningkatan. Pada tes awal rata-rata nilai psikomotorik siswa kelas eksperimen yaitu 37,2581 dan rata-rata nilai psikomotorik tes akhir yaitu 42,4194. Adapun rata-rata nilai psikomotorik siswa kelas kontrol yaitu 33,3871 dan rata-rata nilai psikomotorik tes akhir yaitu 37,8788 . Agar lebih jelasnya, data hasil tes kemampuan psikomotorik siswa disajikan dalam Tabel 3.

Tabel 3. Data hasil tes kemampuan psikomotorik siswa

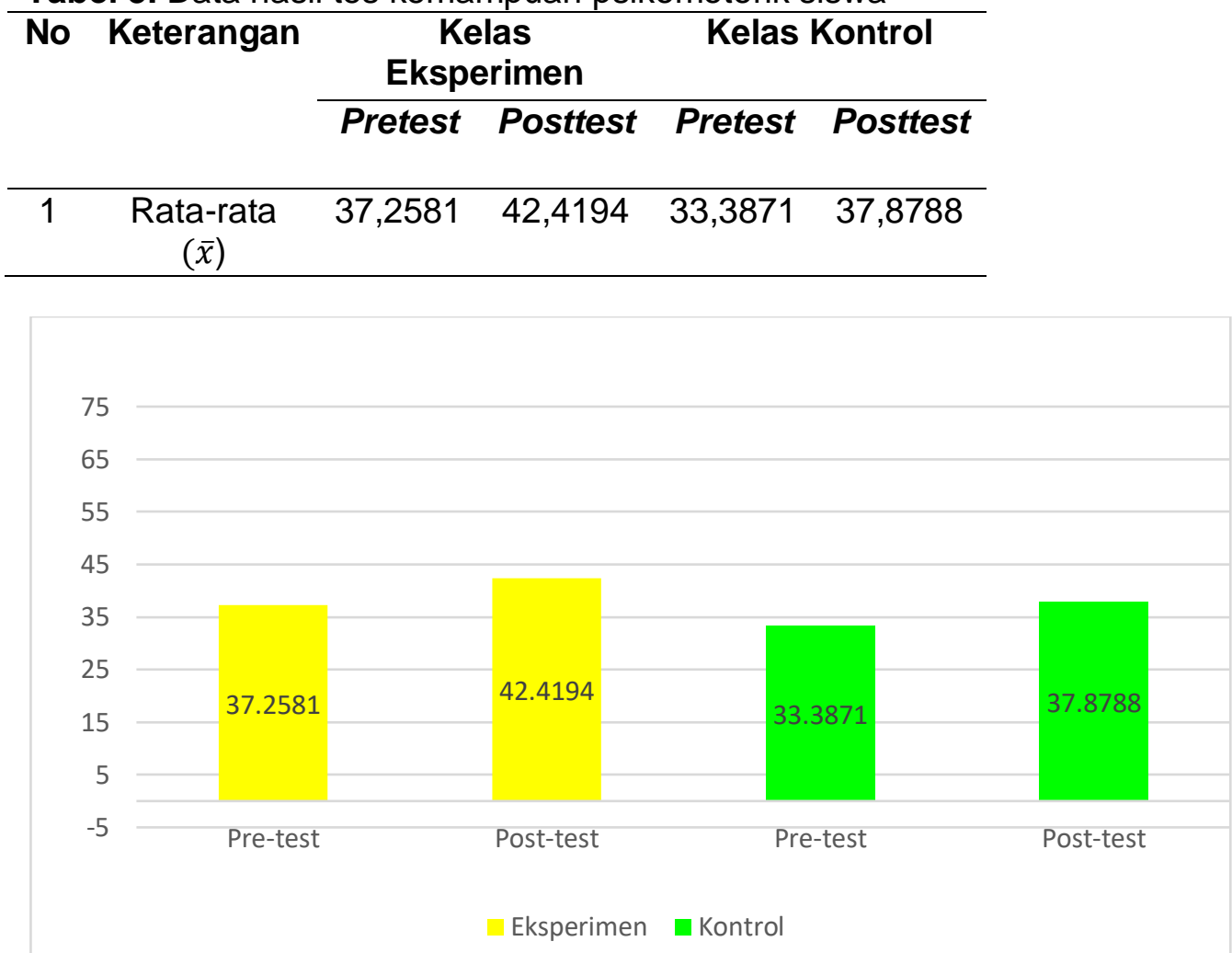

Gambar 3. Diagram data hasil tes kemampuan psikomotorik siswa

Untuk keperluan pengujian hipotesis,terlebih dahulu memerlukan beberapa ujipersyaratan yaitu: (1) uji normalitas dan (2) uji homogenitas. Adapun rangkuman hasil uji normalitas dapat dilihat pada Tabel 4.

Tabel 4. Hasil Uji Pre-test dan post-test Kelas Eksperimen dan Kelas Kontrol

\begin{tabular}{|c|c|c|c|c|}
\hline \multirow{2}{*}{ Simbol } & \multicolumn{2}{|c|}{ Kelas Eksperimen } & \multicolumn{2}{|c|}{ Kelas Kontrol } \\
\hline & Pretest & Posttest & Pretest & Posttest \\
\hline $\bar{X}$ & 37,2581 & 42,4194 & 33,3871 & 37,8788 \\
\hline SD & 8,965782 & 9,4075236 & 8,8741197 & 9,1312212 \\
\hline $\mathrm{X}^{2}$ hitung & $\begin{array}{c}- \\
55,46948\end{array}$ & $-47,8896$ & $-94,5122$ & $-37,889$ \\
\hline$X^{2}$ tabel & 7,815 & 7,815 & 7,815 & 7,815 \\
\hline Keterangan & Normal & Normal & Normal & \\
\hline
\end{tabular}

Berdasarkan perhitungan statistik menunjukkan bahwa pada $\alpha=0,05, X^{2}$ hitung $<X^{2}{ }_{\text {tabel }}$ yaitu pre-test kelas eksperimen $-55,46948<7,815$, maka data pre-test dalam penelitian ini berdistribusi normal. Sedangkan pada $\alpha=0,05, X^{2}$ hitung $<X^{2}$ tabel post-test kelas eksperimen $47,8896<7,815$, maka data post-test dalam penelitian ini berdistribusi normal. 
Berdasarkan perhitungan statistik menunjukkan bahwa pada $\alpha=0,05, X^{2}$ hitung $<X^{2}$ tabel yaitu pre-test kelas kontrol $-94,5122<7,815$, maka data pre-test dalam penelitian ini berdistribusi normal. Sedangkan pada $\alpha=0,05, X^{2}$ hitung $<X^{2}$ tabel post-test kelas kontrol $-37,889$ $<7,815$, maka data post-test dalam penelitian ini berdistribusi normal. Adapun rangkuman hasil uji homogenitas dapat dilihat pada Tabel 5.

Tabel 5. Hasil Uji Homogenitas Pre-test dan Post-test Kelas Eksperimen dan Kelas Kontrol

\begin{tabular}{ccccccc}
\hline \multirow{2}{*}{ Simbol } & \multicolumn{2}{c}{ Data Pre-test } & \multicolumn{2}{c}{ Data Pos-ttest } & \multicolumn{3}{c}{$\begin{array}{c}\text { Data Post-test kelas } \\
\text { Eksperimen dan kelas } \\
\text { kontrol }\end{array}$} \\
\cline { 2 - 7 } & Eksperimen & Kontrol & Eksperimen & Kontrol & Eksperimen & Kontrol \\
\hline $\begin{array}{c}\text { Rerata } \\
\text { (mean) }\end{array}$ & 37,2581 & 31,36 & 42,4194 & $\begin{array}{c}37,878 \\
8\end{array}$ & 42,4194 & 37,8788 \\
\hline Varian & 80,385 & 78,75 & 83,137 & 83,379 & 88,501 & 83,379 \\
\hline$F_{\text {hitung }}$ & 1,010 & & 1,0302591 & 1,06 & 1,84 \\
\hline$F_{\text {tabel }}$ & 1,82 & & 1,82 & Homogen \\
\hline $\begin{array}{c}\text { Keterang } \\
\text { an }\end{array}$ & Homogen & Homogen & & \\
\hline
\end{tabular}

Berdasarkan perhitungan uji homogenitas menunjukkan bahwa pada $\alpha=0,05$, $F_{\text {hitung }}<F_{\text {tabel }}$ yaitu data pre-test kelas eksperimen dan kelas kontrol 1,010<,1,82 maka sebaran data pre-test pada kelas eksperimen dan kelas kontrol dalam peneliti ini bersifat homogen. Sedangkan pada $\alpha=0,05, F_{\text {hitung }}<F_{\text {tabel }}$ yaitu data post-test kelas eksperimen dan kelas kontrol 1,0302591<1,82, maka sebaran data post-test pada kelas eksperimen dan kelas kontrol dalam penelitian ini bersifat homogen. Begitu juga pada $\alpha=0,05$, $F_{\text {hitung }}<F_{\text {tabel }}$ yaitu data post-test kelas eksperimen dan kelas kontrol 1,06 <1,84, maka dapat peneliti simpulkan bahwa sebaran data post-test pada kelas eksperimen dan kelas kontrol dalam penelitian ini bersifat homogen.

Dengan terujinya normalitas dan homogenitas data hasil penelitian, maka syarat untuk keperluan analisis data telah terpenuhi.Selanjutnya pengujian hipotesis dilakukan dengan analisis uji-run menggunakan rumus $z$ hitung karena sampel $>30$. Terdapat perbedaan secara signifikan psikomotorik hasil pre-test siswa antara kelas eksperimen dan kelas kontrol pada pokok bahasan protista kelas X Sekolah Menengah Atas Santun UNTAN tahun pelajaran 2015/2016. Hal ini berdasarkan hasil analisis data dengan uji-run menggunakan rumus Zhitung diperoleh $Z_{0}>Z_{\text {tabel }}, 11,35>1,96$. Dan terdapat perbedaan secara signifikasn psikomotorik hasil post-test siswa antara kelas eksperimen dan kelas kontrol pada pokok bahasan protista kelas X Sekolah Menengah Atas Santun UNTAN tahun pelajaran 2015/2016. Hal ini berdasarkan hasil analisis data dengan uji-run menggunakan rumus Zhitung diperoleh $Z_{0}>Z_{\text {tabel }}, 11,35>1,96$.

\section{SIMPULAN}

Berdasarkan hasil penelitian dan pengujian hipotesis dapat ditarik suatu kesimpulansebagai berikut1) Pembelajaran dengan menggunakan metode eksperimen pada pokok bahasan Protista di kelas eksperimen berdasarkan hasil observasi guru yaitu sangat baik, dan hasil observasi siswa cukup baik. 2) pembelajaran tanpa menggunakan metode eksperimen pada pokok bahasan Protista di kelas eksperimen berdasarkan hasil observasi guru yaitu sangat baik, dan hasil observasi siswa kurang baik. 3) Rata-rata hasil tes awal psikomotorik siswa kelas eksperimen adalah 35,3 dan hasil tes akhir psikomotorik adalah 40,4, dan rata-rata hasil tes awal psikomotorik kelan kontrol adalah 30,90 dan hasil tes akhir adalah 33,04 . 4) Terdapat perbedaan secara signifikan psikomotorik hasil tes awal siswa antara kelas eksperimen dan kelas kontrol pada pokok bahasan Protista kelas X Sekolah Menengah Atas Santun UNTAN Pontianak tahun pelajaran 2015/2016, kesimpulan ini berdasarkan hasil analisis data dengan uji-run menggunakan rumus z-hitung diperoleh z_ $0=1,35>1,96$, dan Terdapat perbedaan secara signifikan psikomotorik hasil tes awal siswa 
antara kelas eksperimen dan kelas kontrol pada pokok bahasan Protista kelas X Sekolah Menengah Atas Santun UNTAN Pontianak tahun pelajaran 2015/2016, kesimpulan ini berdasarkan hasil analisis data dengan uji-run menggunakan rumus z-hitung diperoleh z_0 $01,35>1,96$. 5) Respon siswa setelah menggunakan metode eksperimen pada pokok bahasan Protista di kelas eksperimen mencapai 75,4815 dengan kategori kuat.

\section{REFERENSI}

Ali, M. (1995).Penelitian Pendidikan Pprosedur dan Strategi. Bandung: Angkasa

Amirullah dan Anggita."Pengaruh Aktivitas Bermain dan Perseptual Motorik terhadap Keterampilan Motorik Siswa Sekolah Dasar Kelas Bawah”. Jurnal Pendidikan. Volume 1. Hal 1-15.

Bloom. (1979). Penilaian Ranah Psikomotorik. (Online). Tersedia: http://edukasi.kompasiana.com/2013/11/05/penilaian-ranah-psikomotorik-606857.html. (05 September 2013).

Decaprio Richard. (2013). Aplikasi Teori Pembelajaran Motorik di Sekolah. Jogjakarta: Diva Press.

Dimyati. (2009). Taksonomi Ranah Psikomotor. (Online). Tersedia: http://ekokhoeruln.blogspot.com/2013/02/taksonomi-ranah-psikomotor.html. (Februari 2013).

Ege, B. (2010). Efektivitas Media Lembaran Kartu Kerja (LKK) untuk Meningkatkan Hasil Belajar Siswa pada Materi Ekosistem di Kelas X Sekolah Menengah Atas Negeri 6 Pontianak. Skripsi tidak diterbitkan. Pontianak: Universitas Tanjung Pura.

Ellis Juanne Ormrod. (2008). Educational Psychology Developing Learnes. New Hampshire

Faizi Mastur. (2013). Ragam Metode Mengajarkan Eksakta pada Murid. Jogjakarta: Diva Press.

Hartono, R. (2014). Ragam Model Mengajar yang Mudah Diterima Murid. Jogjakarta: Diva Press.

Heni dan Ratih. "Pengaruh Penggunaan Pendekatan Keterampilan Proses Sains terhadap Psikomotorik Siswa Kelas V dalam Mengikuti Pelajaran IPA di SDN 1 Blora Tahun Pelajaran 2010/2011". Jurnal Pendidikan. Volume 1. Halaman 1-16.

Hurlock.(1996). Journal of Counseling Psycbology. (Online): Tersedia: http://Barrett

Lennard, G. T. (1983). "The Empathy Cycle: Refinement of Psycbology Nuclear Concept".. 28, (2),91-100.

A Journal of Counseling

Jalaludin, Rahmat. (1966). Psikologi Komunikasi. Bandung: Rosda Karya.

Jihad. A dan Abdul Haris. (2012). Evaluasi Pembelajaran. Yogyakarta: Multi Pressindo.

Maryam."Pengaruh Metode Demonstrasi terhadap Keterampilan Proses Sains Siswa Kelas $X$ pada Materi Pencemaran Air Sekolah Menengah Atas Negeri 01 Bukit Tinggi Tahun Pelajaran 2008/2009". Volume 1. Halaman 1-13.

Misbahuddin dan Iqbal. H. (2013). Analisis Data Penelitian dengan Statistik. Jakarta: PT Bumi Aksara. 
Masslamet.R. (2013).3 Unsur dalam Hasil Belajar (Kognitif, Afektif, Psikomotorik).(Online).Tersedia; radenmasslamet.blogspot.com/2011/11/3-unsurdalam-hasil-belajar-kognitif.html (21 Maret 2014).

Nuriman, Mayangsari, dan Agustiningsih. 2012. "Penerapan Metode Eksperimen untuk Meningkatkan Aktivitas dan Hasil Belajar IPA Siswa Kelas VI Pokok Bahasan Konduktor dan Isolator SDN Semboro Probolinggo Tahun Pelajaran 2012/2013". Jurnal Pendidikan. Volume 1. Halaman 1-15.

Palendeng. (2003: 82). Strategi Pembelajaran Eksperimen. (Online). Tersedia: https://ramacahyati8910.wordpress.com/2012/11/15/strategi-pembelajaraneksperimen/. (15 September 2012).

Rachman.(2007). Pengaruh Model Pembelajaran dan Kemampuan Perseptual Motorik. Jakarta: Depdiknas

Riduwan.(2013). Pengantar Statistika untuk Penelitian Pendidikan, Sosial, Ekonomi, Komunikasi, dan Bisnis. Bandung: Alfabeta.

S. Udin. Winartaputra, et al. (2007).Teori Belajar dan Pembelajaran. Jakarta: Universitas Terbuka.

Sagala.(2003). Metode Pembelajaran Eksperimen.(Online). Tersedia: http://aginista.blogspot.com/2013/01/metode-pembelajaran ekserimen.html. (Januari 2013)

Sagala, Syaiful. (2008). Konsep dan Makna Pembelajaran. Bandung: Alfabeta.

Slameto.(2010). Belajar dan Faktor-Faktor yang Mempengaruhinya.Cet IV. Jakarta: Bina Aksara.

Sirath dan Arinanda. "Penerapan Metode Eksperimen untuk Meningkatkan Aktivitas dan Hasil Belajar IPA Siswa Kelas VI pada Pokok Bahasan Konduktor dan Isolator SDN Semboro Probolinggo Tahun Pelajaran 2012/2013". Jurnal Pendidikan. Volume 1. Halaman 1-18.

Slameto.(1995). Belajar dan Faktor-Faktor yang Mempengaruhinya. Jakarta: Rineka Cipta.

Sudjana.(1987). Kelebihan, Kekurangan, Kelemahan dan Cara Mengatasi Metode Pembelajaran Eksperimen.(Online). Tersedia: http://nuraidaayifa.blogspot.com/2014/12/kelebihan-kekurangan-kelemahan-dancara.html. (Desember 2012).

Sugiyono.(2012). Statistika untuk Penelitian.Bandung: Alfabeta

Sugiyono. (2013). Metode Penelitian Kuantitatif Kualitatif dan R\&D. Bandung: Alfabeta.

Supardi. (2012). Aplikasi Statistika dalam Penelitian. Jakarta: Ufuk Press.

Suprapto. (2013). Metodologi Penelitian IImu Pendidikan dan IImu-IImu Pengetahuan Sosial. Jakarta: Center for Academic Publishing Service.

Winkel, W. S. (2009). Psikologi Pembelajaran. Jakarta: Gramedia. 
Yulianti, Taufiq, dan Andriani. 2011. "Pengaruh Pembelajaran Fisika pada Materi Suhu dan Kalor dengan Pendekatan Metode Eksperimen Siswa Kelas VII Sekolah Menengah Pertama Negeri 02 Banjarmasin Tahun Pelajaran 2011/2012”. Jurnal Pendidikan. Volume 1. Halaman 1-17. 